\title{
Crimen organizado y reacción ciudadana: las autodefensas en Michoacán
}

\author{
Jaime Rivera Velázquez* \\ Janeth Valdez Rivera** \\ Guillermo Vargas Uribe
}

Algunas de las organizaciones del narcotráfico en México han diversificado sus negocios y la forma de operar. No sólo trafican con droga sino que dominan territorios, someten a las autoridades y expolian a la población civil. La organización de los Zetas empezó a operar como brazo armado del Cártel del Golfo hasta que rompieron el vínculo. A partir de 2001, los Zetas llegaron a Michoacán a disputar el territorio y, gracias a su alianza con una organización delictiva local, pronto se apoderaron de la plaza. En 2006 esta alianza se fracturó y entonces surgió La Familia Michoacana, organización que adoptó el modelo criminal Zeta y lo revistió con un discurso religioso, moral y de radicalismo social.

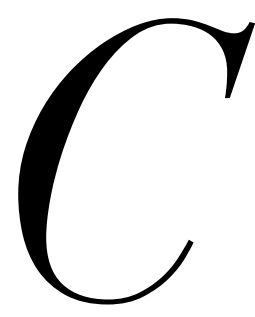

UANDO La Familia logró expulsar a los Zetas, en Michoacán implantó un imperio que - aparte de traficar con marihuana, cocaína y metanfetaminas - sobornó y sometió a las autoridades, y por medio de violencia, amenazas y algunas recompensas expolió a cientos de millares de productores rurales, comerciantes y población en general, para ello recurrió a extorsiones, secuestros, derechos

\footnotetext{
* Facultad de Economía "Vasco de Quiroga", Universidad Michoacana de San Nicolás de Hidalgo.

** Facultad de Economía "Vasco de Quiroga", Universidad Michoacana de San Nicolás de Hidalgo.

*** Facultad de Economía "Vasco de Quiroga", Universidad Michoacana de San Nicolás de Hidalgo.
}

de piso, venta obligada de protección, violaciones, despojos de bienes inmuebles - casas, terrenos, huertas, etcétera-y homicidios.

El imperio de La Familia - y su nueva versión, Los Caballeros Templarios - sometió a pueblos enteros del sur de Michoacán a niveles de explotación y opresión intolerables, y finalmente provocó una reacción organizada de las víctimas. A partir de febrero de 20I3, surgieron los llamados Grupos de Autodefensa para enfrentar a los Templarios. Pronto se extendieron a decenas de municipios. En un principio, el gobierno del estado de Michoacán era hostil a las autodefensas; nada pudo hacer. El gobierno federal primero intentó contenerlas y desarmarlas, pero pronto optó por aceptar su colaboración en el combate a la delincuencia 


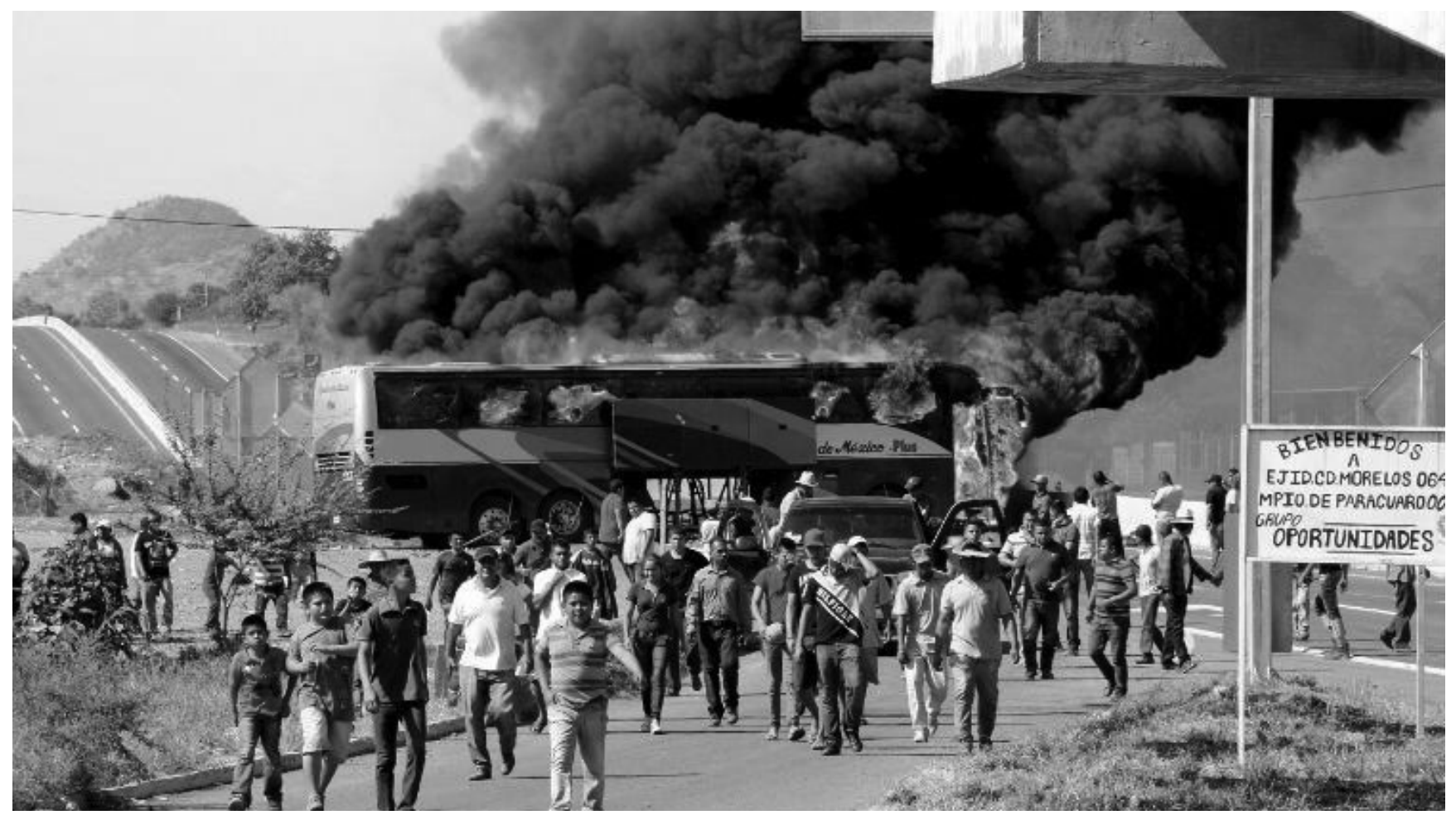

Las organizaciones de traficantes de drogas incendian autobuses, bloquen vialidades

y organizan balaceras para disputar el control territorial y sustraer una renta social.

organizada. A partir de enero de 20I4, la intervención masiva de las fuerzas federales, el virtual desplazamiento del gobierno del estado y la alianza del gobierno federal con las autodefensas produjeron un debilitamiento severo de los Templarios, con la detención o muerte de la mayor parte de sus jefes. Después se implementó el difícil proceso de desmovilización y desarme de las autodefensas, y luego fueron reconvertidas en Fuerzas Rurales estatales, sujetas a la ley y controles institucionales. El proceso no ha concluido; aún está sembrado de riesgos e incertidumbre.

El análisis de las Autodefensas de Michoacán se aborda en cinco dimensiones: las causas que les dieron origen: defensa propia o inducción de fuerzas rivales; la dinámica de su organización y expansión territorial y política; las autodefensas como opción de participación ciudadana para la seguridad; los riesgos de convertirse en nuevas organizaciones delictivas; y las oportunidades de institucionalizarse.

\section{Michoacán: tradición del narco}

Desde la década de I940, el estado de Michoacán - localizado al suroeste de México - empezó a cultivar marihuana, más tarde amapola, para proveer a los exportadores de Sinaloa. El clima y las extensas serranías mal comunicadas y con escasa presencia del Estado favorecían esos cultivos que ofrecían a una población rural pobre - principalmente de la región conocida como Tierra Caliente y de la Sierra Madre del Suruna opción económica más atractiva que los cultivos tradicionales de subsistencia. Durante cuatro décadas, esas actividades se desenvolvieron con relativa tranquilidad; eran ilegales y estaban sujetas a operativos periódicos de erradicación de plantíos y detención de productores por parte del ejército y la policía; pero a la vez eran toleradas por las autoridades, mediante sobornos, y aceptadas por buena parte de los habitantes locales que veían en los cultivos de droga una fuente de derrama económica directa o indirecta. El papel de los productores michoacanos como socios subordinados a los narcotraficantes del norte del país no favorecía la formación de grandes organizaciones delictivas locales. La protección discreta de autoridades locales y federales, de la cual gozó el narcotráfico en México por varias décadas, reforzaba el statu quo de paz en la ilegalidad.

Esta situación empezó a cambiar en la década de I980, con la apertura de las rutas de cocaína en México. Ante el auge de la demanda en Estados Unidos, desde América del Sur ya no sólo operaron las vías aéreas sino también las marítimas por el Pacífico y el Golfo. El largo litoral de Michoacán en el Océano Pacífico 


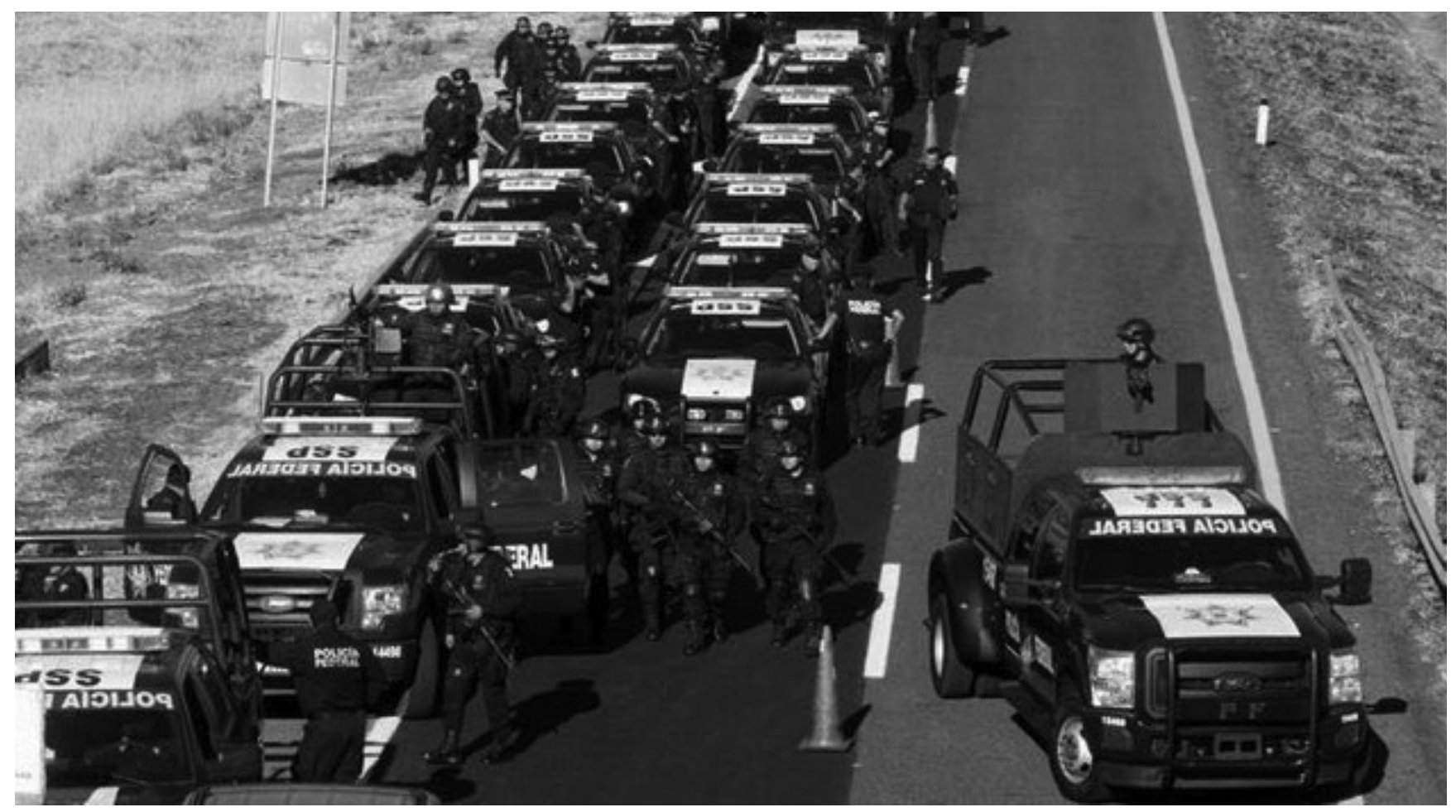

El gobierno federal implementa grandes operativos armados para capturar a los líderes de las organizaciones de traficantes bajo la denominada "guerra contra el narcotráfico".

(23o kilómetros) y el puerto de Lázaro Cárdenas transformaron a esta región en una ruta estratégica para el trasiego de drogas. Además, en los años noventa se introdujo la producción de drogas sintéticas (metanfetaminas), cuyos precursores químicos provienen primordialmente de Asia a través del Pacífico. Así surgió en Michoacán una organización local con pretensiones de cártel, el de Los Valencia, después llamado Cártel del Milenio. Esta organización de narcotráfico prosperó como proveedora de marihuana y cocaína - proveniente de Colombia - a los cárteles de Ciudad Juárez, y más tarde de Tijuana y Sinaloa, y ampliaron su negocio propio con la producción y distribución de metanfetaminas. Los hermanos Valencia eran discretos, nada ostentosos, y empleaban el mínimo de violencia en sus operaciones a fin de no atraer la atención de las autoridades. ${ }^{1}$

Un cambio mayor se produjo a partir de 200I, cuando el brazo armado del Cártel del Golfo, los Zetas, se lanzó a conquistar la plaza de Michoacán. Para los pasos fronterizos de Tamaulipas controlados por esta organización, Michoacán es una posición estratégica por su ubicación en la costa del Pacífico y su relativa cercanía: las ciudades de Matamoros y Nuevo Laredo distan del puerto de Lázaro Cárdenas y de las principales zonas michoacanas productoras de marihuana y amapola, entre ı,ooo y r,200 kilómetros (mientras que
Tijuana y Nogales, en el extremo noroeste de México, controlada por las organizaciones del Pacífico, se encuentran a más de 2,ooo kilómetros de Michoacán). Pero Michoacán ya estaba ocupado por la organización de Los Valencia y sus socios del Pacífico, y los Zetas tuvieron que pelear por él. Buscaron aliados locales en Michoacán y empezaron a disputar la plaza con dosis de violencia que Michoacán no había conocido hasta entonces. En un par de años lograron expulsar a sus rivales, dejando tras de sí centenares de muertos. De esa forma, el Cártel del Golfo se apropió de una codiciada ruta para la cocaína desde la costa del Pacífico hasta Tamaulipas. Además, Michoacán se convirtió en una de las zonas más importantes de producción de metanfetaminas, con cientos de laboratorios diseminados por toda la entidad.

Pero los Zetas no sólo se apoderaron del tráfico de drogas en Michoacán, también compartieron con sus aliados locales - llamados al principio La Empresaun nuevo "modelo de operación criminal", "2 que consiste en agregar al negocio de las drogas el dominio territorial para controlar todos los negocios ilícitos y expoliar a la población por medio del secuestro y la extorsión. Un verdadero sistema de extracción de rentas sociales basado en la amenaza y la violencia. En poco tiempo, extendieron la extorsión a las autoridades municipales de las zonas controladas. A partir de 


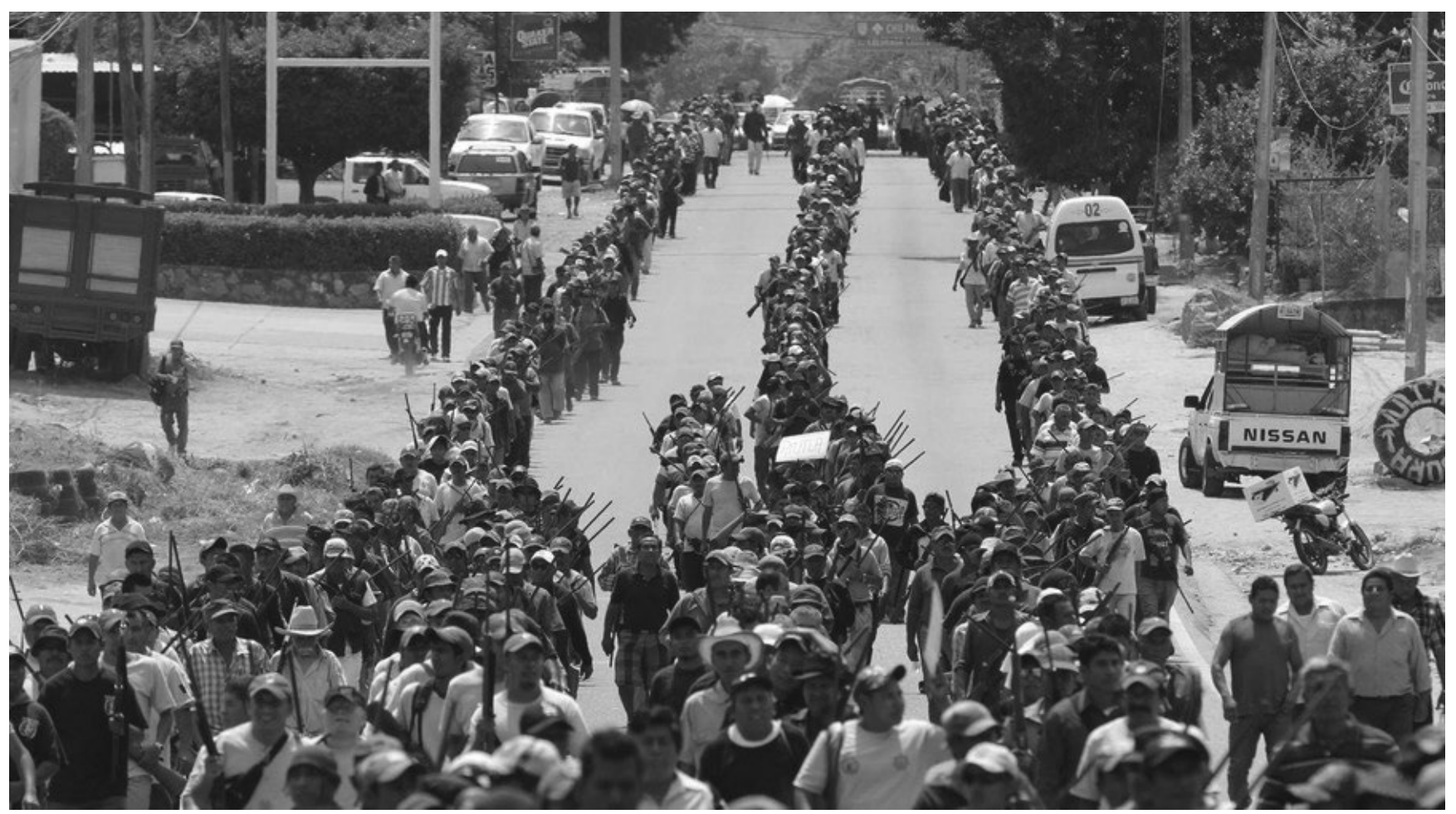

Los ciudadanos afectados por el crimen organizado y desprotegidos por las autoridades se organizan para defenderse.

2002 ó 2003, muchos michoacanos empezaron a dejar de ver al narcotráfico como un fenómeno cercano pero inocuo; en adelante, la delincuencia organizada estaría asociada a tiroteos, amenazas, pago forzado de cuotas, secuestros y, en no pocos casos, a ejecuciones de personas que nada tenían que ver con la delincuencia, salvo como víctimas.

\section{Familia Michoacana}

Los métodos brutales de los Zetas perturbaron radicalmente la forma tradicional de relación de la sociedad local de Michoacán con el narcotráfico. Sus aliados michoacanos, con arraigo en los poblados y relacionados personalmente con mucha gente, veían cundir el miedo y el descontento por la violencia de los Zetas, y decidieron romper con éstos. En 20o6, después de unos meses de disputas internas y centenares de ejecuciones de ambos bandos, salió a la luz pública una nueva organización, La Familia Michoacana. Formada por ex aliados y discípulos de los Zetas, La Familia anunciaría como propósito central liberar a Michoacán de los Zetas. Su debut en la escena pública ocurrió en la ciudad de Uruapan en septiembre de 20o6, cuando lanzaron a la pista de baile de una discoteca cinco cabezas humanas y una cartulina con el mensaje: "La Familia no mata por paga. No mata mujeres, no mata inocentes, sólo muere quien debe morir, sépanlo toda la gente. Esto es justicia divina". ${ }^{3}$ Dos semanas después, varios periódicos locales publicaron un manifiesto de La Familia Michoacana en el que se proclaman los objetivos de imponer el orden, terminar con el secuestro, la extorsión, los robos y los asesinatos, así como con la venta local de drogas sintéticas. En ese manifiesto, además, La Familia se autodefine como una organización integrada por "trabajadores de la región de Tierra Caliente organizados por la necesidad de terminar con la opresión, la humillación... por la gente que siempre ha detentado el poder". 4 Una mezcla singular de lucha contra la delincuencia y bandolerismo social con tintes antigubernamentales.

Durante 2006 y 2007 se desató en Michoacán una nueva guerra entre cárteles - La Familia contra los Zetas - que en el primer año causó más de 5 oo muertos. El especialista en seguridad Eduardo Guerrero estimó 526 ejecuciones en 2006. La intervención de las fuerzas federales, ordenada por el nuevo presidente Felipe Calderón en diciembre de 2006, obligó a los sicarios a replegarse y los homicidios disminuyeron. A principios de 2008 las células del cártel Golfo-Zetas estaban diezmadas y expulsadas. La Familia se quedó con un virtual monopolio del negocio de las drogas en Michoacán.

Ya sin enemigos de consideración en el terreno, los capos y sicarios de La Familia pudieron desplegar libremente su modelo de negocios criminal, en parte 
aprendido de los Zetas, pero con su sello propio. Impusieron el control territorial y el cobro de "derecho de piso" para todas las actividades ilícitas; no tardaron en vender protección y cobrar "impuestos" a agricultores ricos; después extendieron la red de extorsiones a toda clase de personas susceptibles de extraerles recursos: comerciantes establecidos, transportistas, pequeños agricultores, vendedores ambulantes, etcétera; ni las autoridades municipales quedaron a salvo, porque muchos policías fueron sobornados, amenazados y puestos al servicio de la mafia, y los propios alcaldes se vieron obligados a pagar cuotas a La Familia.

Un rasgo peculiar de La Familia Michoacana, que llamó mucho la atención y que inclusive condujo a muchos a justificar sus actividades delictivas, era el discurso religioso, moral y de radicalismo social con el que buscaba justificar sus acciones delictivas y atraerse apoyo popular. Su líder máximo, Nazario Moreno González, alias El Chayo, también apodado "El más loco", combinaba sus decisiones y actos criminales con una doctrina seudo-cristiana de liberación espiritual, superación personal y servicio a los demás. La Tuta, un profesor rural formado en las filas del radicalismo de izquierda del sindicato magisterial, fungía como vocero y propagandista de La Familia, con una retórica antigubernamental, populista y justiciera que también contribuyó a atraer simpatías. Lo cierto es que $\mathrm{La} \mathrm{Fa}$ milia sí logró hacerse de una base social de apoyo. En primer lugar, por su promesa de liberar a la población de las extorsiones, robos y violencia de los Zetas; en segundo, porque los operadores de la nueva organización daban recompensas a quienes les ayudaban con información o como intermediarios para conseguir negocios, y en tercero, porque su oferta de "protección" iba acompañada de amenazas que más valía tomar en serio. Los jefes y "delegados de plaza" de $L a$ Familia aparecían así como autoridad alterna que lo mismo cobraba impuestos, que resolvía controversias entre particulares, ajusticiaba a infractores, patrocinaba fiestas religiosas y sometía a autoridades locales. Eran respetados y temidos. Una variante del estilo siciliano de dominación.

No obstante su retórica moral y religiosa, la violencia era un recurso indispensable del modo de operación de La Familia, como lo es de cualquier grupo dedicado a negocios ilegales. De hecho, esta organización dio muestras de formas extremas y macabras de ejercer la violencia, como exhibir cabezas cercenadas y amontonar cadáveres en la vía pública. Probablemente por su alianza temporal con los Zetas, los jefes de La Fami- lia adoptaron métodos perversos e inhumanos para entrenar a sus sicarios. Se sabe que en las filas de los Zetas hubo antiguos kaibiles, aquellos militares guatemaltecos anti-guerrilla especializados en aterrorizar a la población con los medios más sanguinarios. En 20ıo, la Policía Federal decomisó un video de entrenamiento de La Familia, en el que se observa que a los sicarios se les ordena cortar cabezas de prisioneros ejecutados y cubrirse el cuerpo con la sangre de las víctimas o hasta devorar sus órganos. Eran ritos de iniciación y una manera de hacerles perder el miedo, según el testimonio de un sicario detenido en 2014. ${ }^{6}$

En 2009 y 2010 , la ofensiva federal contra la delincuencia en Michoacán se tradujo en la detención de varios mandos medios de La Familia y decenas de sicarios y colaboradores. A cada golpe de las fuerzas federales, la organización respondía con represalias, como ataques a la policía, bloqueo de caminos, incendios de estaciones de gasolina. En julio de 2009, a raíz de la detención de Arnoldo Rueda, La Minsa, La Familia capturó y asesinó a i2 policías federales que hacían labores de inteligencia. Todos los cadáveres fueron apilados y exhibidos en una autopista. En diciembre de 20Io, las fuerzas federales conjuntas intentaron detener al jefe máximo de La Familia, El Chayo, en una serranía del municipio de Apatzingán, y se produjo una batalla en la que probablemente hubo decenas de muertos. La policía interceptó comunicaciones de los delincuentes que daban por muerto a su jefe, y así lo dio a conocer oficialmente el gobierno, a pesar de no haberse encontrado al cadáver. Mucha gente dudaba de la muerte de El Chayo, y con el tiempo se multiplicaron los testimonios de quienes decían haberlo visto vivo. El 8 de marzo de 20Í, el gobierno federal anunció oficialmente que fuerzas de la Armada dieron con el capo y al tratar de arrestarlo lo abatieron. Esta vez sí contaron con el cadáver, al que le hicieron todas las pruebas de identidad. Un par de meses después, irrumpieron disputas internas en el cártel con una secuela de ejecuciones, y en marzo de 2orr se anunció el surgimiento de una nueva organización denominada Los Caballeros Templarios, enemiga de los restos de La Familia. La facción identificada todavía como La Familia fue desplazada; se refugió en el oriente de Michoacán y en el Estado de México. Su líder, José de Jesús Méndez, alias El Chango, fue detenido en junio de 20Ir. Para mantener el sello de la casa, los Templarios anunciaron que "seguirían con las actividades altruistas que antes realizaba La Familia".? 
En poco tiempo, los Caballeros Templarios se recuperaron de los golpes de la policía y de la escisión, y volvieron a gozar del monopolio del tráfico de drogas y las extorsiones; además, ampliaron sus negocios a la exportación ilegal a China de mineral de hierro (del que despojaban a pequeñas minas) y al contrabando de efedrinas y toda clase de mercancías ilícitas, gracias al control que ejercían sobre el puerto de Lázaro Cárdenas. La dominación de los Templarios se extiende por todas las regiones de Michoacán, desde la Tierra Caliente a la Costa, del Oriente al Bajío, de la Meseta Purépecha a la capital misma del estado. Tal implantación y expansión de su imperio no sería explicable de no haber contado con la complicidad de autoridades de los tres niveles de gobierno.

Comprensiblemente, La Familia y Los Templarios pudieron asentarse y prosperar gracias a la virtual ausencia del poder del Estado o inclusive a la ayuda de algunas instancias oficiales. En poblados rurales de la Tierra Caliente o la Sierra del Sur, el poder estatal siempre ha estado distante y la aplicación de la ley es opcional. Los gobiernos municipales son débiles. El gobierno del estado de Michoacán, con más recursos que los ayuntamientos y facultado para prevenir y perseguir los delitos, fue particularmente omiso durante el periodo de la lucha entre los cárteles. El gobierno federal también fue pasivo o sólo actuaba en la región intermitentemente. Cuando La Familia se consolidó, a partir de 2008 contó con diversas formas de protección del gobierno estatal. Esta organización criminal gozó así de un paraíso: monopolio en el negocio de las drogas y en el control de otros negocios ilícitos, facilidades para expoliar a la población y una impunidad garantizada por la pasividad o complicidad de los gobiernos.

En unos cuantos años, La Familia y Los Templarios lograron tejer una extensa red de control sobre policías y gobiernos municipales, a los que extorsionaban, sometían y ponían a su servicio. Los municipios constituyen el nivel de gobierno más vulnerable a la dominación de la delincuencia, dados sus recursos financieros escasos y sus cuerpos policíacos mal equipados y carentes de normas de control efectivas. Los alcaldes, que generalmente radican en el lugar con su familia, están expuestos a las presiones y amenazas de los mafiosos. Poco pueden confiar en sus propias policías municipales, y han aprendido que de nada les sirve recurrir al gobierno del estado a denunciar y pedir protección, dada su pasividad o complicidad con la delincuencia.

Para muchos presidentes y funcionarios municipales, someterse a las exigencias de la mafia parecía ser casi la única vía de supervivencia. La vinculación de los gobiernos municipales con el crimen organizado ha sido la norma, aunque hay distintas formas de vinculación: la más común es la sumisión pasiva a la extorsión, que se limita al pago de cuotas bajo amenaza - según el testimonio de varios alcaldes, la cuota básica es el ro por ciento de todo el presupuesto para obras públicas, más cuotas extraordinarias variables -; otra es la sumisión activa, mediante el nombramiento de personas ligadas a la delincuencia en puestos clave del gobierno municipal, como la policía y la dirección de obras públicas - el control del área de obras públicas es importante porque Los Templarios manejan empresas que acaparan contratos de los ayuntamientos - , y una más, es la complicidad deliberada, cuando la autoridad protege a los criminales y participa con ellos en negocios ilícitos. Esas distintas formas de vinculación no son excluyentes, sino frecuentemente complementarias; muchos funcionarios pasaron con el tiempo de una a la otra. En no pocos casos, el vínculo se estableció desde antes de las elecciones, por medio del financiamiento ilegal de las campañas.

Puede decirse que la mayoría o todos los gobiernos municipales de Michoacán han estado sometidos o vinculados de alguna forma a los Templarios. Como ejemplos, seguramente entre muchos otros casos, en abril de 20I4 el alcalde de Apatzingán, el municipio que fungió por varios años como la capital del imperio de La Familia y Los Templarios, fue arrestado por la Procuraduría General de la República bajo la acusación de exigir a los regidores una parte de su sueldo para los Templarios, además de forzarlos a firmar la autorización de jugosos contratos para beneficiar a esa organización delictiva. Igualmente, el alcalde de Lázaro Cárdenas, donde se encuentra el estratégico puerto del Pacífico, fue detenido junto con su tesorero por proteger y ayudar a la delincuencia organizada. Varios alcaldes han confesado públicamente que eran obligados a entregar dinero a los Templarios y suponen que todos los demás lo hacían. Como víctimas o cómplices, los gobiernos municipales han contribuido a la implantación de la inmensa red delictiva que exprime a la sociedad michoacana y distorsiona las actividades económicas.

\section{IMPERIO DEL MIEDO Y LAS AUTODEFENSAS}

El uso sistemático de las armas para amenazar y castigar, y del dinero para corromper y compensar, les permitieron a La Familia y los Caballeros Templarios 


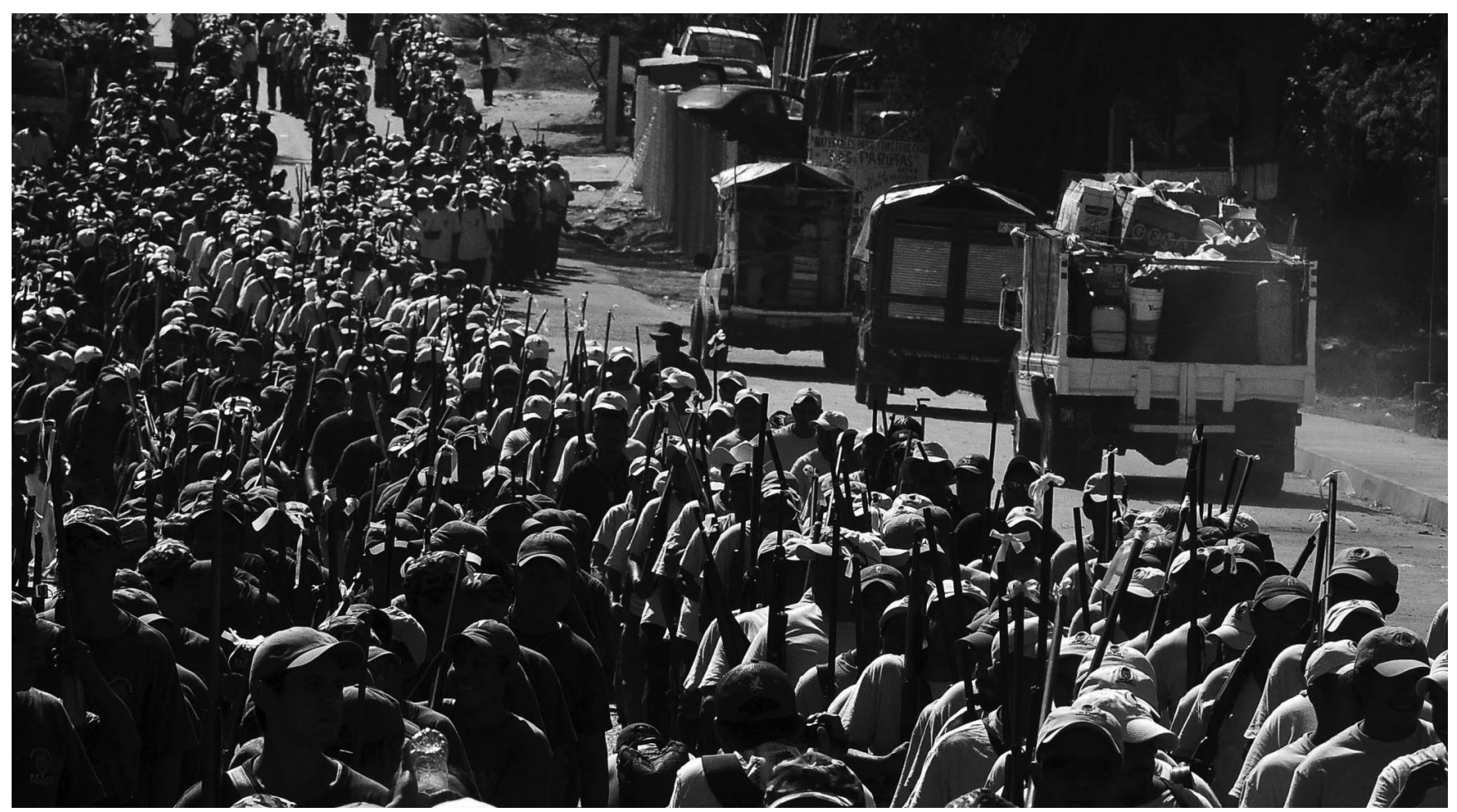

Las autodefensas michoacanas emprenden un recorrido por localidades aledañas para intentar "liberarlas" del crimen organizado.

someter a cientos de miles de personas. Aunque no puede negarse el respaldo social que llegaron a tener en algunas localidades y entre ciertos grupos organizados (taxistas, comerciantes informales, entre otros), el factor más decisivo de su sistema de dominación es el miedo. Puede entenderse cómo construyeron su imperio del miedo: primero, con actos de violencia punitivos y ejemplares homicidios, incendios, secuestros, exhibición macabra de cadáveres); segundo, con amenazas creíbles y castigo a quienes se resisten, y tercero, con la certeza de que no hay autoridad que dé protección a las víctimas. Una vez tejido ese entramado criminal, el miedo se reproduce automáticamente y permite a un reducido grupo de sicarios en cada pueblo someter a sus designios a miles de personas.

Las consecuencias del poderío y la impunidad de la delincuencia organizada han sido devastadoras para la economía, la vida social y la política de Michoacán. Los productores rurales, con su tributo, se convirtieron en siervos de los Caballeros; los empresarios pierden incentivos para invertir; muchos negocios han cerrado y sus propietarios, emigrado; los transportistas foráneos saben que están a merced de los delincuentes; los alcaldes, amenazados por la mafia, desvían recursos para salvar sus vidas - y de paso para beneficiarse personalmente -; los funcionarios estatales, impotentes ante la delincuencia o cómplices de ella, optan por una mezcla de resignación, evasión y cinismo.

El modelo criminal de extracción de rentas parecía imparable. Sin embargo, el propio éxito del sistema templario de explotación lo condujo a su límite. La depredación creció más allá del umbral que podía tolerar la población sometida. Con una analogía biológica, podría decirse que la extracción de recursos por el depredador rebasó la "capacidad de carga" del ambiente, hasta poner en peligro de colapso a todo el ecosistema y provocar nuevas forma de resistencia de las presas. ${ }^{8}$ Así se puede explicar el surgimiento de las autodefensas: una reacción de las víctimas cuando llegaron al límite de la supervivencia.

En febrero de 2013, en los municipios de Tepalcatepec y Buenavista, en el extremo occidental de la Tierra Caliente, se formaron grupos de civiles armados decididos a enfrentarse a los Caballeros Templarios para detener la expoliación de la que miles de pobladores eran víctimas. Se llamaron a sí mismos Grupos de Autodefensa, aunque también se denominan Guardias Comunitarias. El término "guardia comunitaria" se asocia generalmente a comunidades de raigambre indígena. Pero en Michoacán se está usando en muchos poblados indistintamente como sinónimo de los grupos de autodefensa. En el vecino estado de Guerrero, al sur de Michoacán, también se han formado Guardias Comunitarias o Policía Comunitaria para defenderse 


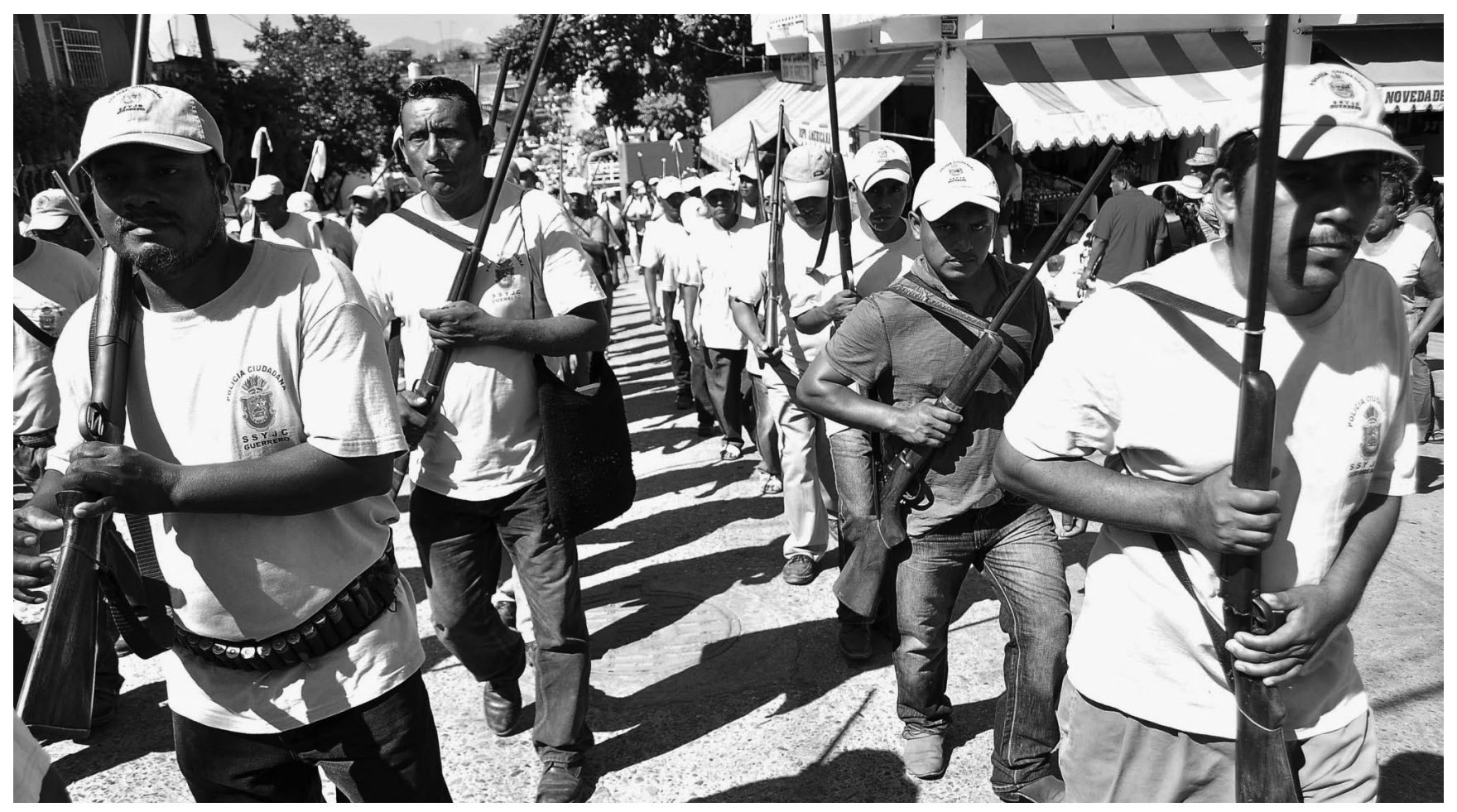

La gente del pueblo se integra a las autodefensas como último recursos para contrarrestar la violencia criminal.

de la delincuencia, aunque algunos de estos grupos parecen tener influencia de grupos subversivos de extrema izquierda. Según su propia justificación, recurren a las armas en defensa propia, cansados de los crímenes y abusos de los Templarios y de la inacción o complicidad de los gobiernos. Unas cuantas semanas después, el ejemplo de Tepalcatepec y Buenavista había cundido en Coalcomán, Aguililla y Chinicuila, en la Sierra del Sur; pronto surgieron grupos de autodefensa en la Costa: Aquila y Coahuayana; inclusive en Yurécuaro, en el extremo norte del estado, se formó una guardia comunitaria. Y, a partir de noviembre de 20ı3, el Consejo de Autodefensas decidió emprender la expansión a muchos municipios más, avanzando sus fuerzas acrecentadas a la Meseta y varios municipios de la Tierra Caliente. A finales de ese año habían ocupado I 7 municipios y en otros siete tenían una presencia periférica; en enero de 2014 ya ocupaban 26 y siguieron avanzando. Tales movimientos de grupos armados ocurrían a la vista de todo el mundo. Las fuerzas federales convivían con las autodefensas en una discreta colaboración mutua, mientras el gobierno del estado (que siempre fue pasivo ante la delincuencia) lanzaba advertencias de "aplicarles la ley".

Aunque los grupos de civiles armados despertaron desconfianza y la sospecha de que eran instrumento de otra organización delincuencial que disputaba el dominio de Michoacán a los Templarios, hay muchos elementos objetivos para afirmar que la causa de los comunitarios es, auténticamente, la defensa propia de la vida, la integridad y la propiedad - y el combate a la delincuencia. Es muy significativo que el ejemplo de las autodefensas se haya expandido rápidamente a otros municipios, donde se observa la adhesión masiva de nuevos voluntarios; en pocos meses o semanas de existencia han logrado la expulsión o repliegue de Templarios de muchos poblados; en casi todos los pueblos que han ocupado, son recibidos como si se tratara de fuerzas de liberación; inclusive algunos alcaldes que parecían coludidos activamente con la delincuencia, apenas llegaron las autodefensas les dieron la bienvenida y repudiaron a los Templarios. Además, su disposición a colaborar con el gobierno federal en las tareas de seguridad permite descartar que tengan propósitos subversivos.

Ello no significa que estos grupos sean puros y homogéneos, ni que no puedan pervertirse con el tiempo. Es muy probable que en el origen de algunos grupos haya influido una organización rival de los Templarios (en particular, el Cártel de Jalisco Nueva Generación), que desearía romper el virtual monopolio de éstos en Michoacán; algunos miembros de las guardias tal vez busquen venganza personal contra quienes les han infligido daño; participan también ex delincuentes, redimidos o no; hay también desempleados, aventureros y pandilleros atraídos por la oportunidad de portar 
armas y sacar ventaja al amparo de una causa popular. El carácter irregular de estos grupos y la laxitud del reclutamiento los exponen a toda clase de infiltración e indisciplina. De hecho, las rivalidades entre ellos mismos empezaron a aflorar. El io de marzo de 2or/4 se suscitaron conatos de enfrentamiento entre dos grupos de autodefensa de Buena Vista, por la presunta autoría intelectual de uno de los líderes, Hipólito Mora, en el asesinato de dos miembros del otro grupo. Hipólito Mora, hasta entonces uno de los principales líderes del movimiento de autodefensas, fue arrestado y se encuentra bajo proceso por esos homicidios. Por otra parte, miembros del grupo de autodefensa del municipio de Yurécuaro fueron detenidos también, acusados de asesinar al alcalde del vecino municipio de Tanhuato. Gustavo Garibay, presidente municipal de Tanhuato, fue muerto a balazos el 22 de marzo de 2or/. Antes, en 20I2, fue herido en un atentado por parte de la delincuencia organizada. Su partido, el Partido Acción Nacional, reclamó a los gobiernos estatal y federal haberle retirado la custodia a pesar de las amenazas del crimen organizado. Aún así, es innegable el papel positivo que las autodefensas han tenido para combatir a los Templarios.

Uno de los motivos de sospecha sobre la índole de las autodefensas es el origen de sus armas y del dinero con el que se sostienen. Aunque no hay que descartar el apoyo por parte de un grupo delictivo, esa hipótesis no es indispensable para el sostenimiento de las guardias. Se debe tener en cuenta que en las zonas rurales de Michoacán y especialmente en la Tierra Caliente, armas siempre ha habido. Dinero, algunos lo tienen, como los productores agrícolas ricos, aguacateros, ganaderos y comerciantes. Para muchos de ellos, extorsionados y despojados por los Templarios, ahora resulta preferible pagar a defensores civiles que seguir pagando a sus expoliadores. Además, para muchas familias que han sufrido extorsión, despojos, homicidios y violaciones, unirse a los grupos de autodefensa o apoyarlos con lo que tengan, puede ser una cuestión de supervivencia. También hay casos de trabajadores emigrados a Estados Unidos que están cooperando con las guardias para proteger a sus familiares. Además, en algunas localidades los comunitarios están pidiendo a los habitantes cooperación económica no del todo voluntaria; de hecho, hay casos aislados en los que están cobrando una suerte de impuestos forzosos para sostenerse, aunque mucho más bajos que lo que cobraban los Templarios. Así, el misterio del patrocinio de los grupos de autodefensa se resuelve si en vez de buscar una fuente única, se suman los factores mencionados.

Lo cierto es que los grupos de autodefensa alteraron sensiblemente las formas de dominación que los Caballeros Templarios habían impuesto desde años atrás. Parecen haber roto el efecto paralizante del miedo al que estaban sometidas amplias franjas de la población. Cuando algunas víctimas, cansadas de los abusos o desesperadas, se reconocieron entre sí y se decidieron a actuar, descubrieron que eran muchos más que sus verdugos y que podían enfrentarlos. La decisión inicial de unos cuantos contagió a miles, porque son decenas de miles los que han sufrido la servidumbre y la violencia del imperio templario. La mayor fortaleza de las autodefensas frente a sus enemigos no son las armas, sino la superación del miedo. Los escasos enfrentamientos con los Templarios que ha habido durante la expansión de las autodefensas, sugieren que los delincuentes son menos fuertes y numerosos de lo que se pensaba; al saberse inferiores en número, han optado por huir y ocultarse. En diciembre de 20I3, en entrevista con Mundo Fox, el jefe templario Servando Gómez Martínez, La Tuta, dijo contar con "unos diez mil muchachos armados", y se jactaba de poder derrotar fácilmente a los comunitarios. La huida de los Templarios ante las autodefensas (que, según ellas mismas, ascienden a 15 mil ó 20 mil), sugiere que se trata más de bluff que de un dato verdadero. La guerra civil que se temía se convirtió en una silenciosa retirada. Con la acción conjunta de las fuerzas federales y las autodefensas, es posible que el miedo se haya transmitido ahora a los delincuentes con un efecto paralizante. Entre las anteriores ofensivas federales contra la delincuencia en Michoacán y la de 2014, la diferencia principal está en las autodefensas. Otra diferencia es que, esta vez, el gobierno federal neutralizó y terminó sustituyendo de hecho a las policías locales, evitando así fugas de información que podían alertar a los delincuentes.

\section{INTERVENCIÓN FEDERAL}

El nuevo presidente de la República, Enrique Peña Nieto - con el que el Partido Revolucionario Institucional volvió al poder nacional después de i2 años - se afanaba en restar visibilidad al problema de la delincuencia organizada. No es que no quisiera combatir al crimen, pero, a diferencia de su antecesor Felipe Calderón del Partido Acción Nacional, ha tratado de ma- 
nejar el problema de la seguridad en forma más discreta. Tal vez por esa razón, durante varios meses no prestó mucha atención a la inseguridad y la espiral de violencia que asolaban a Michoacán. O quizá no aquilataba suficientemente la crisis en la que estaba sumido ese estado, que no sólo padecía inseguridad, sino desórdenes sociales y una ineficacia del gobierno estatal alarmante. Michoacán sufre desde años atrás una crisis de seguridad y gobernabilidad, o mejor dicho, una crisis institucional de la que los michoacanos parecen incapaces de salir por sí mismos. ${ }^{9}$

Fue necesario que el mundo observara en Michoacán una espiral de violencia - con ataques a las fuerzas federales y atentados a estaciones eléctricas por parte de la delincuencia organizada - y, sobre todo, el avance de los grupos de autodefensa a una veintena de municipios y los augurios de una virtual guerra civil, para que el gobierno federal optara finalmente, a partir del i3 de enero de 20r4, por una intervención masiva de la Policía Federal, el Ejército y la Marina, y la virtual suplantación del gobierno estatal por un comisionado federal, Alfredo Castillo Cervantes, con amplios poderes en materia de seguridad y gasto público.

La primera tarea de las autoridades federales en Michoacán ha sido tratar de restablecer el orden y la seguridad por medio de la ocupación policíaca y militar de los principales territorios dominados por los Templarios para inhibir su acción y, de ser posible, arrestarlos. A este respecto, la intervención federal puede anotarse varios logros importantes: además de la detención de varios centenares de presuntos sicarios o colaboradores de los Caballeros Templarios, ha arrestado a los capos Jesús Vázquez Macías, El Toro, y Dionisio Loya Plancarte, El Tío, entre otros mandos medios, además de matar a Nazario Moreno El Chayo, jefe máximo de la organización, y al operador financiero Enrique Plancarte. De los principales jefes de los Templarios, a finales de abril sólo quedaba prófugo Servando Gómez La Tuta, aunque las fuerzas federales parecían estar cerrando el cerco para capturarlo.

En el propósito de acabar con los Caballeros Templarios, el gobierno federal ha optado por la colaboración con los grupos de autodefensa, a pesar de su carácter ilegal. El gobierno desistió de desarmar por la fuerza a las guardias, porque ello causaría costos políticos y humanos inaceptables. El gobierno federal está convencido de que en esos grupos predominan las intenciones auténticas de combatir a la delincuencia organizada; además, los considera útiles para amedrentar a los Templarios y ayudar a localizarlos. "Su mayor ayuda no es con armas, sino con información", ha dicho el comisionado federal Alfredo Castillo. Y parece que esa ayuda ha sido eficaz. Por lo menos en los municipios ocupados por las autodefensas, las extorsiones han disminuido drásticamente. Por primera vez en varios años, miles de michoacanos se sienten libres de trabajar para sí mismos. Una frase sintetiza la nueva situación que, al parecer, se está creando en Michoacán: "Ya no tenemos que pagar cuotas".

De todos modos, los grupos de autodefensa no son una solución aceptable en un Estado de derecho ni podrán seguir operando indefinidamente. Grupos civiles armados sin reglas estrictas de reclutamiento, sin mandos centralizados ni disciplina eficaz conllevan muchos riesgos: infiltración de delincuentes, abusos contra la población, venganzas personales, conversión de algunos grupos en nuevas mafias. Seguramente el gobierno está consciente de esos peligros, pero se ha visto obligado a contemporizar con ellos. Se trata de aliados inesperados, incómodos, útiles temporalmente, pero difíciles de controlar y cargados de riesgos explosivos. El gobierno federal trataba de contener el avance de las autodefensas y éstas insistían en expandir su área de influencia. Ambas partes se necesitan, desconfían una de la otra y forcejean por ganar terreno, pero sin romper la alianza.

Ya que el gobierno no quería utilizar la fuerza para desarmar a las autodefensas, les ofreció una opción intermedia: disolverse como grupos independientes, y convertirse en Cuerpos de Defensa Rurales o en un nuevo tipo de policía rural, sujetos a la ley y a un mando institucional. Al principio, sólo una minoría aceptó esa opción, pero es muy probable que más grupos prefieran la institucionalización al desarme.

Finalmente, el gobierno federal, por medio del comisionado Alfredo Castillo, parece haber encontrado una solución más radical. El í4 de marzo llegó a un acuerdo con varios de los líderes de las autodefensas que fija un plazo para el desarme y la virtual disolución. Tal acuerdo ha enfrentado resistencia de otros líderes y de las bases de las guardias, pero gradualmente ha ganado aceptación y adhesiones de los comunitarios. De los dos líderes más notables del movimiento de autodefensas, la posición conciliadora la representan Hipólito Mora y Estanislao Beltrán, conocido como Papá Pitufo, mientras la posición más intransigente, pero al final dispuesta a pactar con el gobierno, era encabezada por José Manuel Mireles. Al final, Mireles - el principal líder fundador de las autodefensas desafió abiertamente al gobierno con una tentativa de 


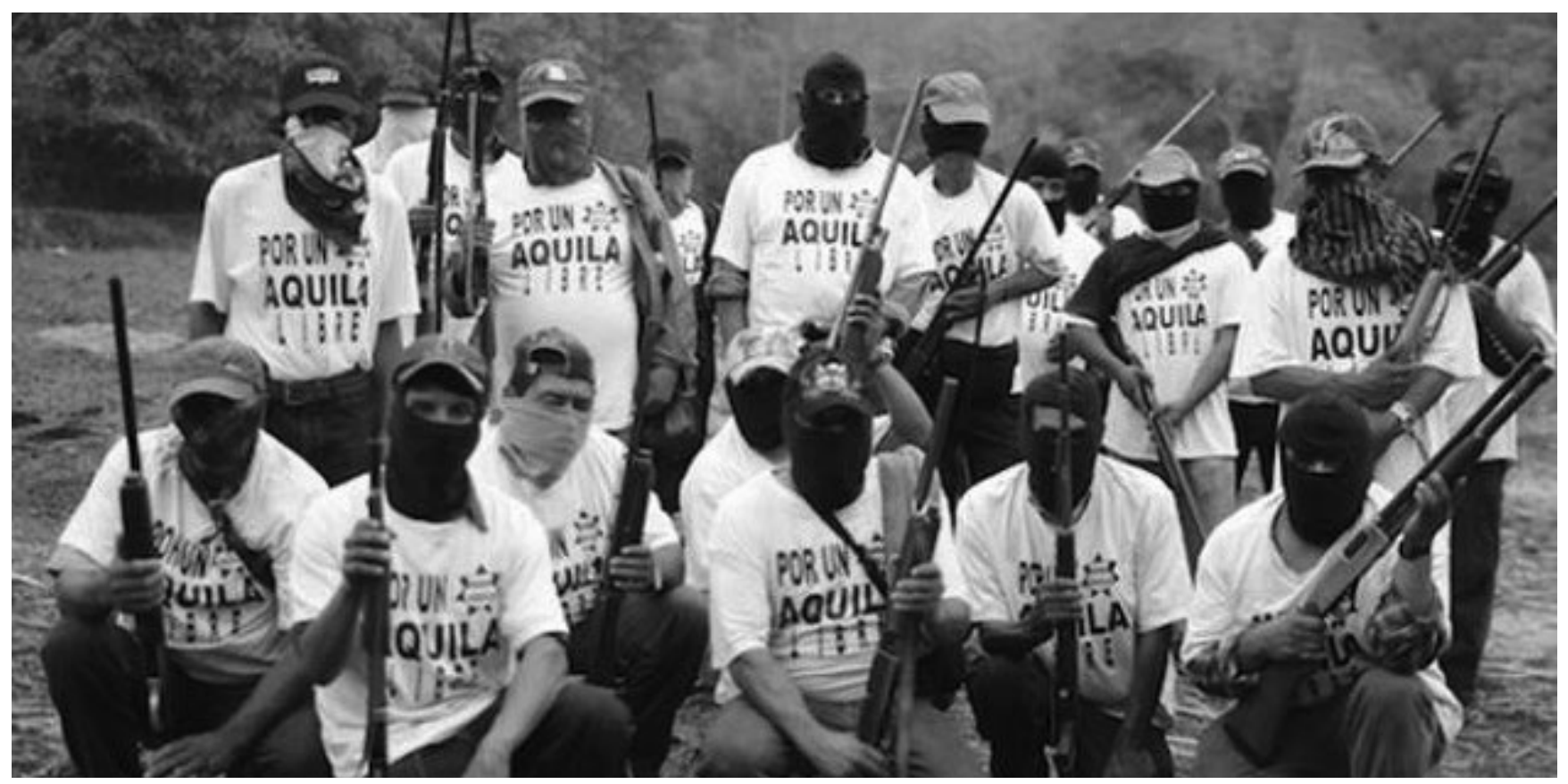

Las autodefensas michoacanas emprenden un recorrido por localidades

aledañas para intentar "liberarlas" del crimen organizado.

tomar con sus guardias la ciudad de Lázaro Cárdenas, y fue detenido, junto a un grupo numeroso de seguidores, por la Policía Federal y sometido a proceso.

Otra línea de acción del gobierno federal, de la mayor importancia, ha sido identificar y desmantelar la protección que desde instancias de gobierno se ha brindado a la delincuencia organizada. El 4 de abril, la Procuraduría General de la República detuvo a Jesús Reyna García, secretario de gobierno y ex gobernador interino, por sus presuntos vínculos con los Templarios. En junio, el gobernador Fausto Vallejo se vio obligado a renunciar, ante el escándalo del presunto involucramiento de uno de sus hijos con el crimen organizado. En julio, se difundió un video que confirmó la relación de Rodrigo Vallejo, alias El Gerber, con La Tuta; días después fue arrestado y se encuentra bajo proceso, acusado de encubrimiento.

Paralelamente, las autoridades federales han actuado penalmente contra varios presidentes municipales. Han sido arrestados los presidentes municipales de Apatzingán (PRI), Lázaro Cárdenas (PRD), Huetamo (PRI) por brindar protección a la delincuencia. También se encuentra bajo investigación la presidenta de Pátzcuaro. Según el comisionado Castillo, están en curso otras indagaciones que podrían conducir a nuevas detenciones de funcionarios.

Después de varios meses de intervención, los Templarios se han replegado y parecen debilitados. Sin embargo, la incidencia delictiva se mantiene ele- vada, e inclusive en algunos delitos se ha incrementado; de hecho, las cifras de homicidios se han elevado. ${ }^{10}$ Según reportes del Sistema Nacional de Seguridad Pública, en el primer trimestre de 2014 se registraron 272 homicidios dolosos, lo cual equivale a un incremento de 55 por ciento sobre el mismo periodo de 2013. Esto se debe, por un lado, a los enfrentamientos entre las fuerzas federales o las autodefensas con los delincuentes y, por el otro, al desplazamiento de los grupos delictivos de las zonas ocupadas hacia otras ciudades, como Morelia, capital del estado. En particular, es significativo el aumento de los delitos en la capital del estado: en el primer bimestre los homicidios crecieron 62 por ciento, y en otros delitos se observan alzas semejantes.

\section{Conclusiones}

Los grupos de autodefensas se explican como una reacción ciudadana de defensa propia y supervivencia de sociedades locales, ante la incapacidad de los órganos del Estado para enfrentar eficazmente a la delincuencia organizada. Además, abundan evidencias de la complicidad de numerosos funcionarios - y funcionarias-, tanto de los gobiernos municipales como del gobierno estatal, incluidos el hermano de un gobernador, el hijo de otro gobernador y hasta un gobernador interino, entre otros. 


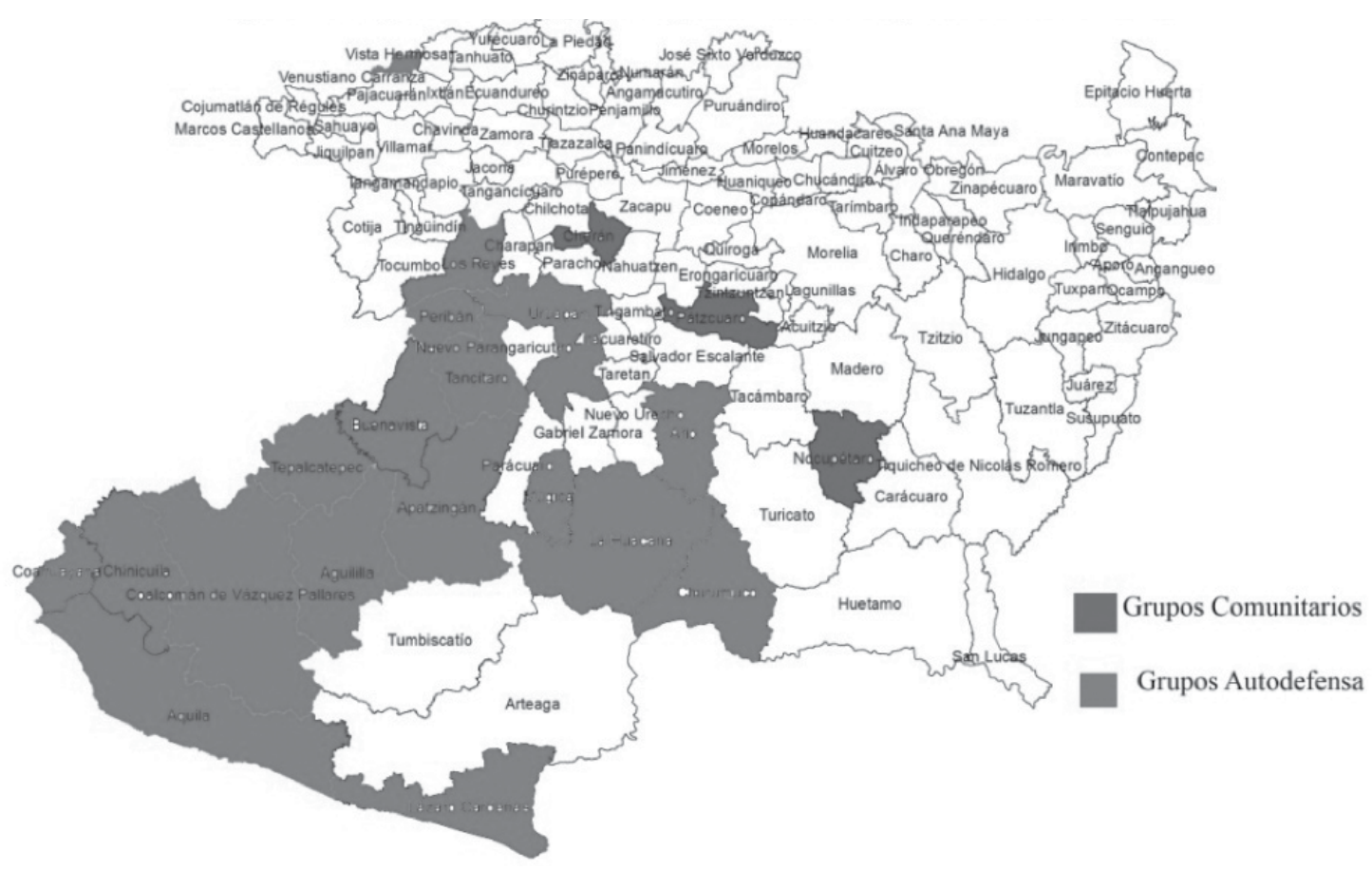

La intervención federal casi ha decapitado al cártel de los Templarios, arrinconado a sus sicarios y dificultado los mecanismos de extorsión, sería prematuro anunciar la erradicación del crimen organizado y su sistema de explotación. Las raíces de este mal son profundas y sus tentáculos se extienden por todo el territorio michoacano y hasta las esferas mismas de los gobiernos.

La institucionalización de las autodefensas, por medio de su conversión en Fuerzas Rurales (nuevo cuerpo de la policía estatal), es un proceso muy complicado, que enfrenta apoyo de unos, resistencias de otros, y en cualquier caso, es un experimento cargado de riesgos.

La experiencia de los grupos de autodefensa es un ejemplo de la capacidad que puede tener la propia sociedad para tomar en sus manos funciones de seguridad pública. Sin embargo, tal opción sólo puede ser excepcional y transitoria. La responsabilidad del Estado en esta materia es intransferible.

\section{- notas $\cdot-$}

' Ricardo Ravelo (2005), Los capos. Las narco-rutas de México, México, Debolsillo, pp. 196-204.

'Guillermo Valdés (2013), Historia del narcotráfico en México, México, Aguilar, pp. 257-26r.

${ }^{3}$ La Jornada Michoacán, 7 de septiembre de 2006.

${ }^{4}$ Valdés, op. cit., pp. 267-269.

${ }^{5}$ Eduardo Guerrero (2012), "La estrategia fallida", Nexos, núm. 420.
${ }^{6}$ El Universal, i8 de marzo de 20I4.

7 El Universal, io de marzo de 20 II.

${ }^{8}$ Vandermeer and Goldberg (2003), Population Ecology. First principles, New Jersey Princeton, University Press.

9 Jaime Rivera (2013), "El abismo michoacano", Nexos, núm. 429 .

${ }^{\circ}$ Alejandro Hope (24 de abril de 2014), "Michoacán: el mito de la pacificación", El Universal. 